\title{
A Proposed Framework for Optimised Utilisation of Materials for Low Volume Roads Using the Dynamic Cone Penetrometer
}

\author{
Michael Pinard ${ }^{*}$, Philip Paige-Green², Jon Hongve3 ${ }^{3}$, Estime Mukandila ${ }^{4}$ \\ ${ }^{1}$ Infra Africa Consultants, Gaborone, Botswana \\ ${ }^{2}$ Department of Civil Engineering, Tshwane University of Technology, Pretoria, South Africa \\ ${ }^{3}$ Independent Consultant, Tjome, Norway \\ ${ }^{4}$ Real Baobab (Pty) Ltd, Pretoria, South Africa \\ Email: ^mike@mipinard.com
}

How to cite this paper: Pinard, M., Paige-Green, P., Hongve, J. and Mukandila, E. (2021) A Proposed Framework for Optimised Utilisation of Materials for Low Volume Roads Using the Dynamic Cone Penetrometer. Journal of Transportation Technologies, 11, 14-36.

https://doi.org/10.4236/jtts.2021.111002

Received: November 18, 2020

Accepted: January 3, 2021

Published: January 6, 2021

Copyright (๑) 2021 by author(s) and Scientific Research Publishing Inc. This work is licensed under the Creative Commons Attribution International License (CC BY 4.0).

http://creativecommons.org/licenses/by/4.0/

\begin{abstract}
In order to minimise the cost of constructing low volume roads (LVRs), it is essential that optimum use is made of locally available, naturally occurring materials. However, conflicts often arise between material acceptability, as defined by conventional test methods and specifications, and material suitability in terms of actual engineering performance as a "fit-for-purpose" road construction material. To avoid such conflicts, it is crucial to adopt appropriate test methods and specifications for selecting construction materials. This paper presents a materials evaluation framework for optimizing the utilisation of materials in LVR pavements based on the use of the Dynamic Cone Penetrometer (DCP). This approach enables materials to be selected on the basis of their "fitness-for-purpose". It avoids suitable materials from being rejected based on one or other of the traditionally specified parameters not being complied with, even though their strength, as measured by the DCP penetration rate ( $\mathrm{DN}$ value in $\mathrm{mm} / \mathrm{blow}$ ) of the soil, may be adequate. Investigations of the properties of a wide range of locally available materials that have been used successfully in the construction of LVRs have confirmed the validity of the materials evaluation framework.
\end{abstract}

\section{Keywords}

Low Volume Roads, Dynamic Cone Penetrometer, Materials,

Fit-for-Purpose 


\section{Introduction}

Naturally occurring soils, gravel soil mixtures, and gravels occur extensively in many tropical and sub-tropical climatic zones. They typically account for about $35 \%$ to $40 \%$ of a low volume road (LVR) cost in many countries. While there is no standard definition of an LVR, it is defined in this paper as one that has a base year average annual daily traffic (AADT) of up to 300 motorised, 4-wheeled vehicles, including about $20 \%$ to $25 \%$ commercial vehicles, and a related traffic loading of up to about one million Equivalent Standard Axles (MESA) per lane ( $\geq 3.5 \mathrm{~m}$ wide) over a design life of typically 15 years.

In the context of LVRs, unprocessed materials are a valuable resource as they are relatively cheap to exploit compared, for example, with processed materials such as crushed rock, and are often the only source of material available within a reasonable haul distance of the road alignment. In order to minimise construction costs and, ultimately, life-cycle costs, maximum use must be made of these materials for the affordable upgrading of unpaved roads to paved LVRs. However, the challenge often faced by designers in attempting to use local materials more extensively is that the use of traditional test methods and the application of traditional specifications have often resulted in their rejection even though practice may have shown that they may be "fit-for-purpose" for use and perform successfully within a given LVR environment [1]. This situation highlights the need to find appropriate and reliable test methods that would facilitate the selection and more wide-spread use of local, natural materials to construct LVRs.

Fortunately, there is a wealth of information derived from the back-analysis of the performance of numerous LVRs in a variety of environments in several tropical and sub-tropical countries [2] [3] [4] [5]. This has not only identified many anomalies in the previous understanding of the relationship between material properties and performance but has also questioned many of the accepted paradigms associated with the selection, testing and specification of materials for incorporation in LVR pavements.

\subsection{Purpose and Scope}

The purpose of this paper is to present a comprehensive evaluation framework for testing and selecting materials based on their "fitness-for-purpose". Extensive research work has been carried out on various aspects of materials testing, evaluation and performance. However, such work has not previously been drawn together in the manner presented in this paper. This has enabled this new evaluation framework to be developed.

The paper firstly discusses the function and general requirements of fit-forpurpose materials, followed by the shortcomings of the traditional approaches typically adopted to test and select materials for LVRs. The authors then present a new approach for evaluating the potential suitability of local materials for incorporation in LVR pavements based on the use of the Dynamic Cone Penetro- 
meter in preference to the more traditional California Bearing Ratio (CBR) test. Finally, factors to be considered for minimising the risk of using locally available, naturally occurring materials are also discussed.

\section{Requirements of Pavement Materials}

For a pavement structure to perform satisfactorily, the materials used must provide the following attributes [6] [7]:

- Sufficient stability in terms of strength and stiffness to withstand repeated cycles of vertical stress without excessive deformation or failure, and retain these former attributes with time (durability) under various environmental influences.

- Sufficient bearing capacity to support the loads transmitted from the pavement structure. This is achieved through:

- Adequate thickness of material required to protect the subgrade for given traffic levels.

o Sufficient inter-particle friction and shear strength, which are material-dependent and influenced by the degree of lateral confining stresses, density and moisture.

Figure 1 illustrates conceptually the role of materials in dispersing the stresses applied to the pavement surface by traffic loading to ensure the pavement's satisfactory performance. The higher the material stiffness, the more effectively the traffic stresses are reduced to acceptable levels in the underlying base, subbase, and on to the subgrade. This will avoid excessive pavement deflections or permanent deformation (rutting) under the moving wheel loads, which would otherwise adversely affect the pavement's performance.

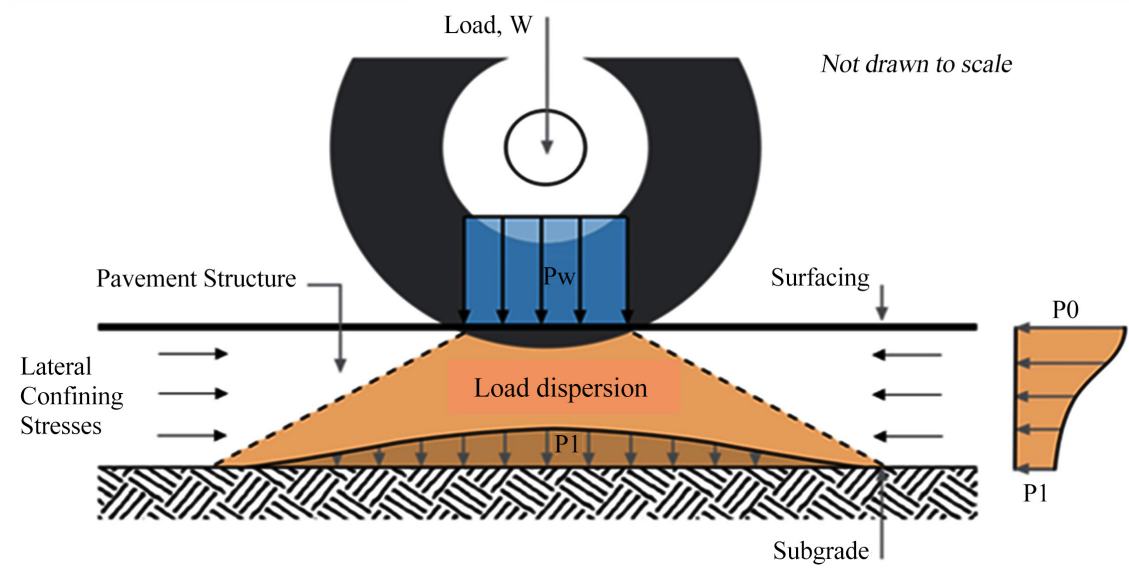

Figure 1. Dispersion of surface load through a granular pavement [8].

\subsection{Operating Environment}

The pavement's operating environment includes environmental impacts, particularly moisture and temperature, and stresses induced by traffic loads. The pavement material must withstand these stresses without significantly changing its form or relevant properties during the road's construction and service life. 
These requirements influence the choice of materials used in terms of their basic properties. However, as illustrated in Figure 2, in the case of LVRs, environmentally induced distress through climatic influences significantly impact pavement performance, proportionately more so than traffic loading, up to about 1 MESA. This underscores the importance of adopting appropriate drainage measures to mitigate the adverse effects of moisture ingress into the pavement structure and understanding how the strength of the material changes under the influence of moisture and compacted density.

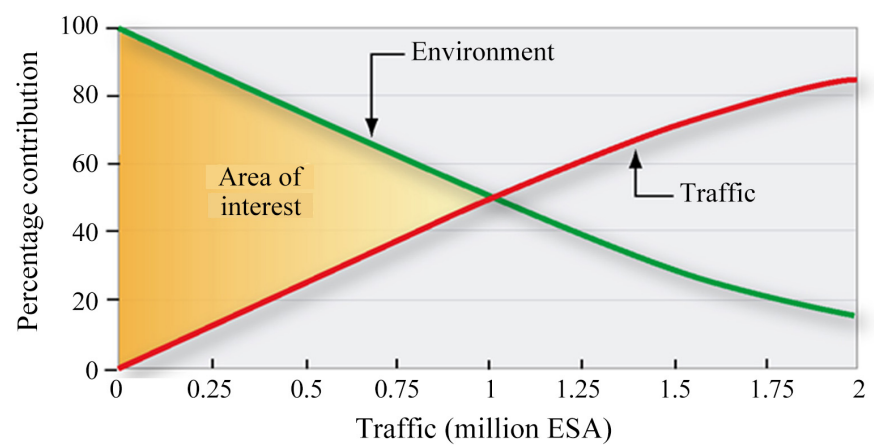

Figure 2. Traffic loading versus mechanisms of pavement distress (Schematic) [9].

\subsection{Properties of Fit-for-Purpose Materials}

A "fit for purpose" material may be viewed as one that exhibits properties and performance characteristics that are directly suited to the chosen design application. The use of such a material provides an optimum balance between risks and costs and, in so doing, should provide excellent value for money. The expected traffic loading and environmental factors, mostly moisture-related, will determine how such materials will perform in service. Thus, understanding what influences the performance and evaluating the associated risk is key to the successful use of fit-for-purpose materials in LVR pavements [10] [11].

Although knowledge of the successful use of fit-for-purpose materials has been gained over many years, it is only relatively recently that extensive systematic testing and evaluation have been carried out through the back-analysis of their in-service performance [2] [3] [4] [5]. Collectively, detailed investigations were undertaken into the performance of more than 175 test sections located in East, West and Southern Africa. The test sections encompassed a wide variety of mostly "non-standard", naturally-occurring gravels (granite, quartzite, dolerite, diabase, sandstone, calcrete, ferricrete, etc.) acting under a range of traffic loading (0.04 - 20 MESA with the majority of roads carrying relatively light traffic (<300 vpd) and environmental conditions (annual rainfall $300 \mathrm{~mm}$ to $>1600$ $\mathrm{mm}$ ). The key findings of the investigations, as related primarily to materials properties affecting LVR pavement performance, may be summarised as follows:

- The general trend is that the in-service moisture content is usually lower than the Modified AASTHO Optimum Moisture Content (OMC). 
- None of the standard indicator tests, such as grading and plasticity, significantly correlate with road performance.

- The only parameters with consistent correlation with performance are the field/optimum moisture content ratio, drainage, traffic, in situ wet density, climate, compaction and gravimetric moisture (note that five of these are related to moisture content-indicative of the role of drainage.

- The range of particle size distributions of the base and subbase materials of satisfactorily performing LVR pavement were both much finer and much coarser than the traditional specification envelopes.

- Most of the pavement failures were caused by unmaintained defects of the surfacings (high pothole and crack intensities) but were non-structural.

- Many road bases failed to meet the standard laboratory CBR strength requirements but still performed well in service.

- The prevalence of excessive moisture within the pavement structures results in problems almost irrespective of the quality of the materials.

- No material property is likely to predict the performance of a LVR without taking drainage, compacted density, overloading, and maintenance into account.

- In general, sections with relatively high crown heights (the vertical difference between the crown of the road and the invert of the side drain) $\geq 0.75 \mathrm{~m}$ generally performed better than sections with lower crown heights, except where coarse or sandy materials were used in the pavement layers or the surrounding materials were permeable or "free-draining".

The main findings from the investigations indicate a lack of correlation between the traditionally specified parameters and performance, which often results in perfectly suitable materials being rejected because of their non-compliance with the combined requirements of grading, plasticity and strength. Thus, it is clear that conventional assumptions regarding the parameters used for selecting materials and the manner of specifying their acceptable limits are unreliable and need to be replaced if better use is to be made of naturally-occurring materials in LVRs.

\section{Materials Testing and Selection}

The key properties of a material that exert a significant influence on the performance of a flexible pavement include:

- Shear strength.

- Stiffness (Resilient Modulus).

Both strength and stiffness indicate stability and are generally dependent on moisture content and density, as influenced by soil suction and material fabric [12], and stress conditions. In contrast, stiffness, or resistance to deformation under load, can change with repeated loading and with weathering or degradation of the material, were it to occur during the service life of the pavement.

The primary material properties, other than materials strength, in terms of CBR, that are commonly considered to influence, rather than control, performance include [13]: 
- Particle size distribution (PSD).

- Plasticity Index (PI), or Linear Shrinkage (LS).

- Combinations of PI and PSD, e.g., Plastic Modulus (PM).

The above properties all have an influence on the strength or stiffness of the material under different combinations of moisture, density, and traffic loading and are inherent in the strength/stiffness determination. Thus, assessing the influence on pavement performance as affected by various combinations of material properties, rather than discrete properties, is essential to properly evaluate material for the intended purpose.

\subsection{Measurement of Materials Properties}

\subsubsection{Strength and Stiffness}

For mechanistic pavement design methods, a quantitative evaluation of the mechanical properties of unbound materials, in terms of their strength and stiffness, is required and is typically determined by carrying out one or other of the following tests [14].

- Strength.

o Static Triaxial.

o Direct Shear.

o Hveem Stabilometer.

- Stiffness.

o Repeated Load Triaxial.

o Resilient Modulus.

o Resonant Column.

Due to the high costs of the relatively sophisticated equipment required to carry out most of these tests, coupled with the complexity of undertaking the actual test, they are generally not appropriate for use in resource-scarce road agencies in most countries in Africa and Asia. Moreover, even in developed countries, the results are often determined from correlations with other basic strength properties or even assumed. Thus, recourse is usually made to use the following relatively cheap and simple "proxy" tests for determining material strength.

- California Bearing Ratio (CBR).

- Dynamic Cone Penetrometer (DCP).

\subsubsection{California Bearing Ratio}

The California Division of Highways originally developed the CBR test around 1930 to provide a method of comparing the strength of natural granular materials with an engineered, well-graded crushed stone (thus, a high-quality crushed stone would have a CBR of about 100\%). It was subsequently developed to assess subgrades for pavement design purposes [15] and is probably the most widely used method for designing LVR pavement structures in tropical and sub-tropical countries.

The CBR test can be described as a mini plate load test in which the standard $50 \mathrm{~mm}$ diameter plunger acts as a circular footing, which, under constant loading applied at a specified rate, eventually causes the material to deform. The re- 
sulting output of the test, the CBR value, is naturally biased towards the material under the plunger (approximately $1.5 \times$ diameter of the plunger or about 75 $\mathrm{mm}$ ) and provides an index of the material's strength. Despite its wide-spread use, the CBR test suffers from several problems, including:

- Poor reproducibility with an overall coefficient of variation of the order of 20 per cent [16]. This characteristic makes the interpretation of test results, especially for inherently variable natural gravels, very imprecise. For example, for an actual mean value of 80 , the CBR can range from 48 to 112-a range that can lead to vastly different interpretations of the soil's suitability for use as a pavement material and either acceptance or rejection of inappropriate or suitable material respectively. Such variability led Rallings [17] to conclude from his investigations that "continuing reliance on the CBR hinders the development of pavement technology".

- It does not measure any of the fundamental engineering properties of soil that critically influence its performance, such as elastic stiffness (Er) or resilient modulus (Mr) [18] [19]. Because the CBR test is so widely used, empirical correlations with elastic stiffness have emerged, including, for example, Er $=10 \mathrm{CBR}[20]$ and $\mathrm{Er}=17.6 \mathrm{CBR}^{0.64}$ [21], and are often used in design computations in the absence of more accurate data. However, as indicated in Figure 3 [22], for a given CBR value, there is a wide range in resilient modulus values (derived from repeated load triaxial tests) depending on the plasticity of the soils. Thus, the typically used empirical relationships provide only a rough guide to the expected soil stiffness in that they tend to overpredict or under-predict resilient modulus [23]. As a result, materials with the same CBR could have very different elastic stiffnesses and, in similar service conditions, could perform quite differently because of their different load-spreading ability.

- The CBR is an empirical value and does not accurately relate to any of the fundamental properties governing material strength or stiffness. The material in the test is predominantly subject to shear deformation but stops short of complete shear failure. The CBR is commonly referred to as a strength and material classification parameter [24].

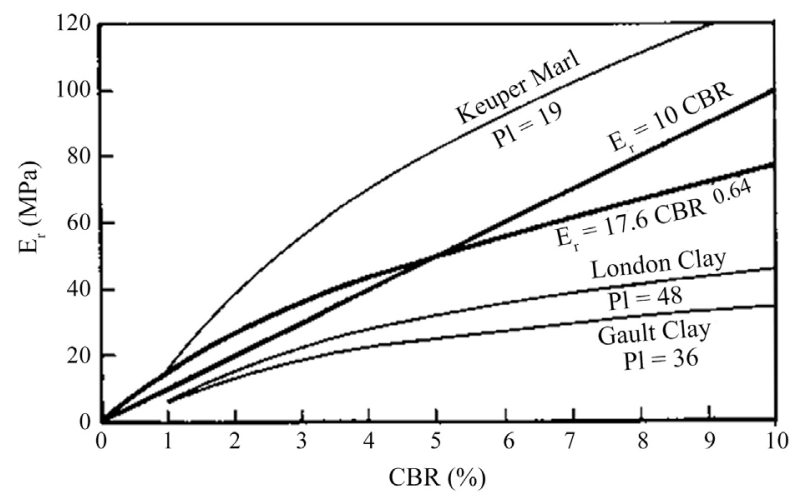

Figure 3. Relationship between elastic stiffness and CBR for a stress pulse of $40 \mathrm{kPa}$ [22]. 


\subsubsection{Dynamic Cone Penetrometer}

The DCP is a relatively simple, low-cost device that is quick and easy to use both in the field, for comprehensive characterisation of the in-situ road conditions down to a depth of about $800 \mathrm{~mm}$, or in the laboratory on samples compacted in a CBR mould. The device is used for measuring a penetration rate in millimetres per blow while the cone is being driven into the material, which causes the development of a shear failure zone.

The repeatability and reproducibility of the DCP test, which is governed by an ASTM standard [25], are reported to be high [26] and to be about 33\% better than that of a CBR test [27] [28]. Both the field and laboratory DN values (the weighted average penetration rate in $\mathrm{mm} / \mathrm{blow}$ of the DCP through a pavement layer) are deemed to be more accurate than the CBR value because the DCP provides a virtually continuous strength profile throughout the depth of the material being tested. Figure 4 illustrates the key features of the DCP device, while Figure 5 shows a typical in-situ strength/stiffness profile of an existing pavement structure showing a progressive decrease in stiffness, which is reflected by an increase in the DCP penetration rate ( $\mathrm{DN}$ value).

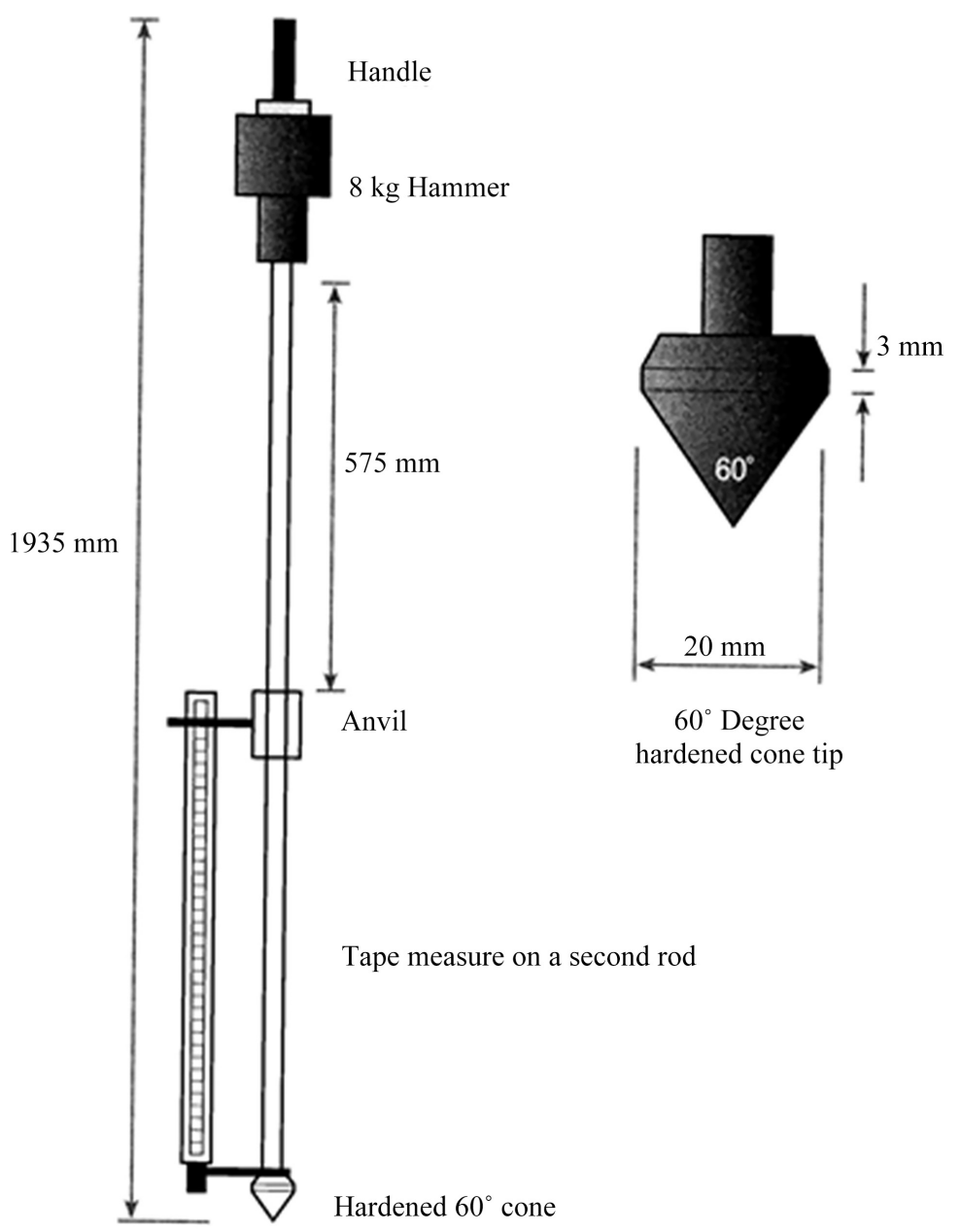

Figure 4. The DCP device. 


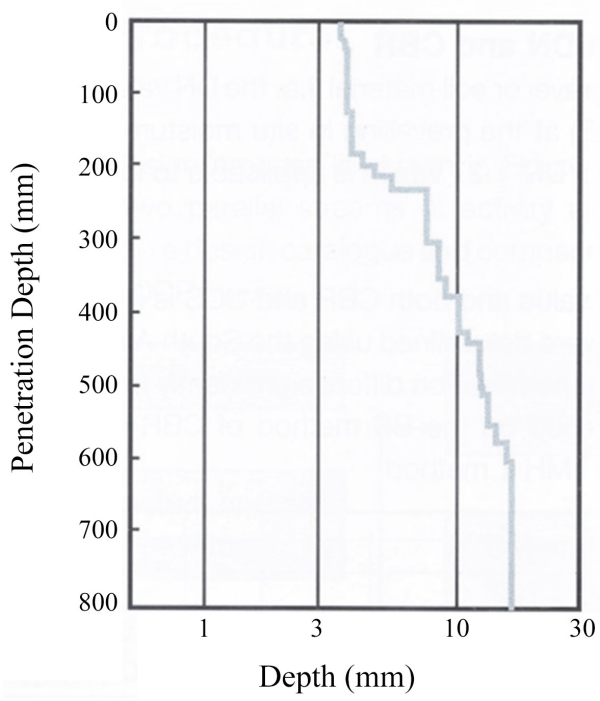

Figure 5. Layer strength profile.

Like the CBR test, the DCP does not measure any fundamental properties of a material. However, the following correlations between the DCP penetration rate (PR) (DN value) and both shear strength and stiffness are noteworthy:

DCP correlation with shear strength: Based on laboratory DCP and rapid triaxial shear tests carried out on re-moulded specimens, Ayers et al. [29] investigated the DCP PR to shear strength correlations for a range of granular materials compacted at three density levels. The granular materials included sand, sandy gravel, and crushed dolomitic ballast with different percentages of fines. Ayers et al. developed material-specific correlations for each material and target density. Table 1 is a sample of the developed equations for single and multiple independent variables for different material types.

Table 1. Samples of single and multiple linear variable regression equations [29].

\begin{tabular}{|c|c|c|c|c|}
\hline Material & $\begin{array}{c}\text { Confining Pressure } \\
\text { (PSI) }\end{array}$ & Regression Equation & $\begin{array}{l}\text { Coefficient of } \\
\text { Determination }\end{array}$ & $\begin{array}{c}\text { Standard Error } \\
\text { of Estimate }\end{array}$ \\
\hline \multicolumn{5}{|c|}{ Single variable regression equations } \\
\hline \multirow{3}{*}{ Sand } & 5 & $\sigma \mathrm{d}=41.3-12.8 \mathrm{PR}$ & 0.998 & 0.3 \\
\hline & 10 & $\sigma \mathrm{d}=100.4-23.4 \mathrm{PR}$ & 0.998 & 0.5 \\
\hline & 15 & $\sigma \mathrm{d}=149.6-12.7 \mathrm{PR}$ & 0.978 & 0.9 \\
\hline \multirow{3}{*}{$\begin{array}{l}\text { Sandy } \\
\text { gravel }\end{array}$} & 5 & $\sigma \mathrm{d}=51.3-13.6 \mathrm{PR}$ & 0.992 & 1.9 \\
\hline & 10 & $\sigma \mathrm{d}=62.9-3.6 \mathrm{PR}$ & 0.997 & 0.3 \\
\hline & 15 & $\sigma \mathrm{d}=90.7-5.8 \mathrm{PR}$ & 0.975 & 1.5 \\
\hline \multicolumn{5}{|c|}{ Multiple linear variable regression equations } \\
\hline Dense & 5 & $\sigma \mathrm{d}=2777-105.7 \mathrm{PR}-18.0 \mathrm{e}+1.6 \gamma-1575 \mathrm{Cu}$ & 0.859 & 18.1 \\
\hline Graded & 10 & $\sigma \mathrm{d}=4474-148.7 \mathrm{PR}-29.1 \mathrm{e}+1.8 \gamma-2411 \mathrm{Cu}$ & 0.893 & 22.7 \\
\hline Materials & 15 & $\sigma \mathrm{d}=5392-179.9 \mathrm{PR}-34.8 \mathrm{e}+2.2 \gamma-2983 \mathrm{Cu}$ & 0.941 & 21.2 \\
\hline
\end{tabular}

$\sigma \mathrm{d}=$ deviator stress $(\mathrm{psi}), \mathrm{PR}=$ penetration rate $(\mathrm{mm} / \mathrm{blow}), \mathrm{Cu}=$ coefficient of uniformity $(-), \gamma=$ density of soil (lbs/cu. $\mathrm{ft})$. 
The conclusions drawn from this study were:

- The DCP test may be used to estimate the shear strength of a variety of granular materials using the prediction equations developed.

- Factors such as moisture and density are implicitly accounted for in the single variable equations because a direct, inverse linear relationship exists between the PR and shear strength.

- Detailed characteristics, such as gradation, maximum aggregate size, density, and void ratio, are not required to predict shear strength from DCP data, although they improve prediction accuracy.

- The use of a DCP device in the manner described in the paper is a viable alternative to detailed in situ test pit investigations; such tests are rapidly conducted and inexpensive.

DCP correlation with stiffness (Resilient Modulus): George and Uddin [30] undertook a study to investigate the use of a DCP device for subgrade soils characterisation, in terms of Resilient Modulus (MR) - a measure of the elastic properties of the soil. The researchers classified a total of 180 samples from 12 test sections into fine- and coarse-grained soils according to AASHTO M145-87.

The prediction of Resilient Modulus (MR) using the DCP penetration rate $(\mathrm{PR}=\mathrm{DN}$ value $)$ was as follows:

- For fine-grained soils

$$
\mathrm{MR}=a_{0}(\mathrm{PR})^{a 1}\left(\gamma_{r}^{a 2}\right)+\left(\mathrm{LL} / w_{c}\right)^{a 3}
$$

$\mathrm{R}^{2}=0.71$, Root Mean Square Error $(\mathrm{RMSE})=31.6$

- For coarse-grained soils

$$
\mathrm{MR}=a_{0}\left(\mathrm{PR} / \log c_{u}\right)^{a 1}\left(w_{c r}^{a 2}+\gamma_{d r}^{a 3}\right)
$$

$\mathrm{R}^{2}=0.72$, Root Mean Square Error $(\mathrm{RMSE})=12.1$

where $\gamma_{d r}=$ Density ratio, field density/maximum dry density

$w_{c}=$ Actual moisture content (\%)

$c_{u}=$ Coefficient of uniformity

$w_{c r}=$ Moisture ratio, field moisture/optimum moisture

$a_{0}, a_{1}, a_{2}$ and $a_{3}=$ Regression coefficients

The main conclusion drawn from the study was that the DCP offers a viable alternative to other more complicated and time-consuming procedures in characterising subgrade soil stiffness through its significant correlation with laboratory resilient modulus.

De Beer [31] carried out extensive work using the Heavy Vehicle Simulator (HVS), which involved parallel testing of the DCP penetration rate and effective elastic modulus in various pavement layers based on multi-depth deflection measurements. De Beer produced a correlation between the effective elastic modulus (stiffness under the varying confining conditions, (Eeff) and the DCP penetration rate $(\mathrm{DN})$, showing the relationship between the two properties, as illustrated in Figure 6. The relationship between the two properties is as follows:

$$
\log \mathrm{E}=3.04758-1.06166(\operatorname{LogDN})\left(n=86 \text { and } R^{2}=0.76\right)
$$




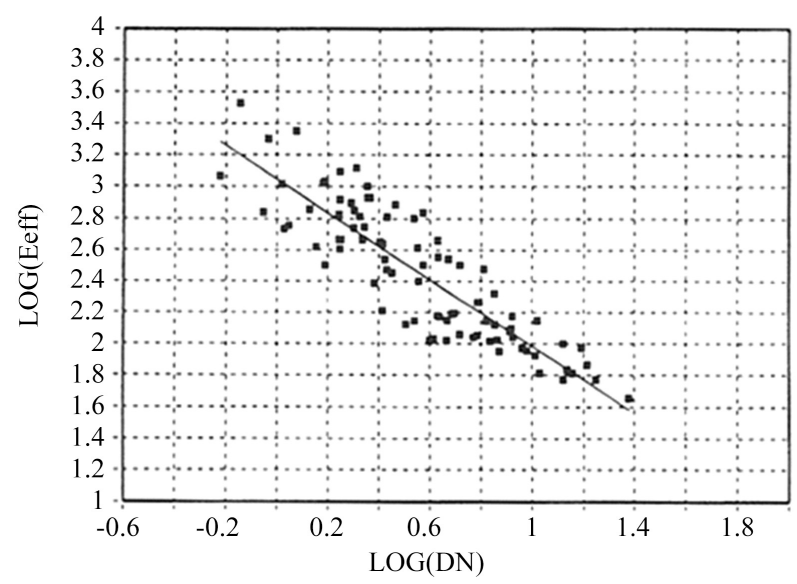

Figure 6. Plot of effective elastic modulus (Eeff) against DCP penetration rate (DN) [31].

Effect of maximum particle size: Like the CBR test, the impact of the maximum particle size of the material on the DCP penetration rate has an impact. Different ways of handling the material larger than $20 \mathrm{~mm}$ are used in different test standards and apply to both test methods. However, it should be noted that the maximum particle size has a significant influence on material stiffness. Repeated load triaxial tests were carried out in a specially constructed cell that could test gravel and sand mixtures up to $90 \mathrm{~mm}$ maximum size [31]. The resilient moduli reported were about $25 \%$ higher for well-graded material with a maximum size of $90 \mathrm{~mm}$ than material with a maximum size of $16 \mathrm{~mm}$. This indicates that the DCP penetration rate of materials with coarse aggregate removed will always be conservative in terms of stiffness compared to the actual field value.

\subsection{Selection of Materials}

Traditionally, the selection of naturally occurring granular materials for use in pavement layers is initially by classification tests, which include particle size distribution (grading envelope, maximum particle size), particle durability (soundness), fines plasticity (Plasticity Index, Plastic Modulus, Linear Shrinkage) and swell. In addition, a strength requirement, traditionally derived from the CBR test, is also imposed. An indication of the probable suitability of material is then generally assessed by compliance with specification limits placed on these material properties, which are meant to exclude the most unsatisfactory ones from incorporation in the road pavement.

As concluded in Section 2.3 above, applying traditional parameters for testing, specifying and selecting materials for incorporation in LVR pavements often gives rise to conflicts between material acceptability, as defined by the specification and material suitability in terms of its actual engineering performance. As a result, satisfactory performance has been obtained from materials that do not meet the specified requirements. Conversely, poor performance has been ob- 
served with materials that satisfy the specified requirements [3] [4]. This suggests that the application of traditional specifications for selecting naturallyoccurring materials developed mainly for temperate-zone material characteristics that have been modified for LVRs, is unreliable, apart from the fact that the imposition of these multiple property requirements tends to exclude the use of a range of fit-for-purpose materials. Such a situation could arise because of:

- Specification of materials properties based on index tests that broadly reflect their properties, but are not directly related to their performance.

- Testing of materials that do not reflect in their in-service state (density and moisture content).

The above issues give rise to a larger concern-the efficacy of using an assortment of materials properties, such as grading, plasticity and CBR, which are not performance-related, as evidenced by the outcome of the back-analysis of many LVR pavements. Moreover, the relatively large coefficient of variation $(\mathrm{CoV})$ associated with the related tests $(\mathrm{CBR}: \mathrm{CoV}=18 \%$, PI: $\mathrm{CoV}=74 \%$, Grading: $\mathrm{CoV}=31 \%$ [32], and a possible accumulation of errors, especially in poorly resourced laboratories in many tropical/subtropical countries, make it all the more pressing for the use of a more reliable evaluation framework. Such a framework should include a good characterisation test that is more closely linked to performance for assessing the suitability of materials for incorporation in LVR pavements.

\section{Materials Evaluation Framework}

The proposed approach to the evaluation of subgrade/earthworks and pavement layer materials is based on consideration of the following:

- Knowledge of the key engineering properties of the subgrade/earthworks and pavement materials in order to detect those materials with deleterious properties associated with "problem soils", such as excessive swell, erodibility, salinity, or collapse potential. This is obtained from traditional classification, grading, and other appropriate tests carried out on bulk samples obtained from the existing pavement and borrow areas.

- The selection of materials in terms of acceptability for specific use in the subgrade or pavement layers is then based on engineering judgment related to the outcome of the above tests, bearing in mind the preference for local material use on LVRs

- Knowledge of the key parameters required in a pavement layer-the shear strength and stiffness of the material-are a function of the material properties, including grading, plasticity, aggregate hardness, etc. Whilst the DN is strongly correlated to the shear strength of a material [29], neither the DN nor the CBR have been shown to correlate strongly with stiffness [22] [30] [31]. Thus, because of its strong correlation with shear strength, and its better reproducibility [26], the DN is deemed to be the more reliable parameter for evaluating the suitability of materials, as described in the evaluation framework in Section 4. 


\subsection{Evaluation of Materials}

A subgrade or pavement material's strength is broadly influenced by its basic properties (grading, plasticity, aggregate hardness, etc.). However, the strength of such materials is also influenced by the operating conditions in the pavement and will vary with moisture content, compacted density and prevailing stress conditions. Therefore, to fully understand how a material is expected to perform under a specific design scenario, and ultimately how fit for a particular purpose it will be, it is necessary to examine how the strength of the material, as influenced by its basic properties, varies with different combinations of moisture content and density and, thereafter, to assess the risk associated with the design assumptions. This can be achieved by adopting a 3-tiered evaluation framework (Figure 7) as follows:

\section{Stage $1-$ Materials screening}

This stage's objective is to screen out, through appropriate testing, obviously unsuitable or problematic materials.

\section{Stage 2-Materials evaluation}

This stage aims to evaluate the suitability of materials in terms of their strength, as related to various combinations of moisture and density, for comparison with the design requirement.

\section{Stage 3-Risk assessment}

This stage aims to assess how a material responds to density and moisture content changes to evaluate the implications of such changes on the operational conditions in service.

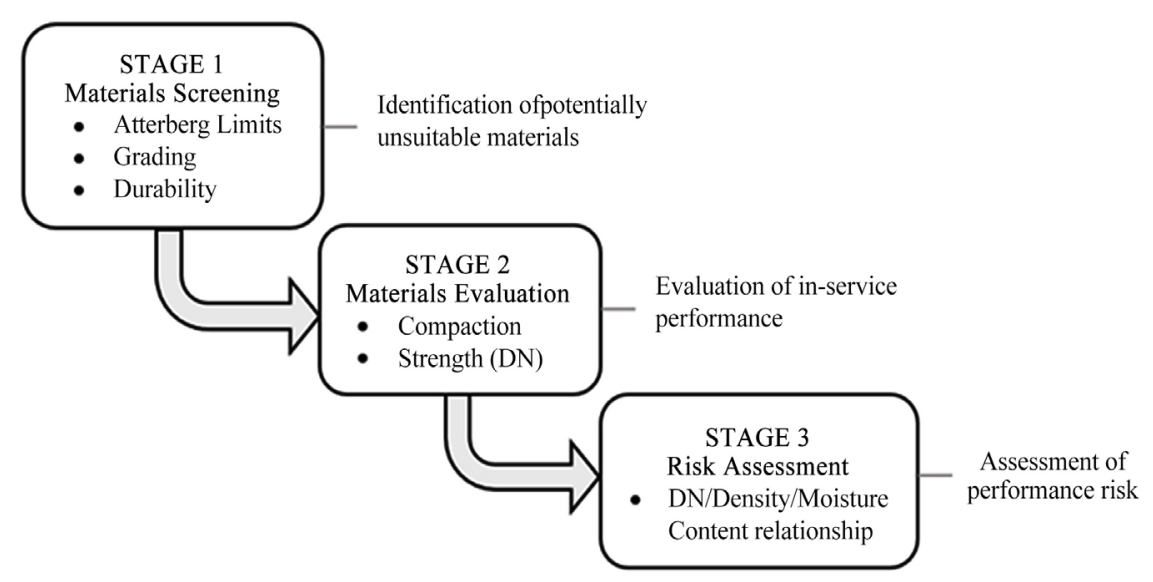

Figure 7. Materials evaluation framework.

The various stages of the materials evaluation framework entail the undertaking of several laboratory tests indicated in Figure 7, following standard local testing procedures, as follows: 


\section{Stage 1-Materials Screening}

Screening of subgrade or pavement layer materials is firstly made to detect and eliminate those with deleterious properties associated with "problem soils", such as expansive, erodible, saline, etc., using appropriate tests, as described below [11].

Atterberg Limits: The standard tests to determine this parameter, i.e., Plastic Limit (PL), Liquid Limit (LL), Plasticity Index (PI) and Shrinkage Limit (SL), must be carried out to provide a first indication of how a material will react under various moisture conditions, but they give little indication of the strengthmoisture-density relationship that will be separately investigated in Stage 2 . Nonetheless, the PI and LL are useful indices for determining the swelling characteristics of most fine-grained clay soils [33] whilst the classification of swelling potential of clayey soils can be determined from their LL and PI [34].

Grading: The Grading Modulus (GM) of the material is also required for excluding overly fine or coarse materials from being considered for use in the pavement layers. The following formula calculates the GM:

$$
\mathrm{GM}=[300-(\mathrm{P} 2+\mathrm{P} 425+\mathrm{P} 075)] / 100
$$

where P2, P425 and P075 denote the percentages passing through the $2.0 \mathrm{~mm}$, $0.425 \mathrm{~mm}$ and $0.075 \mathrm{~mm}$ sieve sizes, respectively.

The particle size distribution determination should be based on a wet sieve analysis, with pre-treatment being required for pedogenic materials, such as calcretes and laterites.

Mineralogical and durability tests: The use of weathered materials of basic igneous origin, such as basalt and dolerite, is potentially problematic, although less so for LVRs with relatively short lives of typically 15 years, as they may decompose in service to various degrees as a result of the alteration of certain primary minerals to secondary clay minerals. Thus, appropriate durability tests (usually involving soaking in ethylene glycol) may need to be carried out in accordance with country standards.

Final assessment: The selection of materials in terms of acceptability for a specific use is then based on consideration of the results of Stage 1 of the laboratory testing programme, coupled with engineering judgment, bearing in mind the preference for using local materials.

\section{Stage 2-Materials Evaluation}

Once acceptability of the material is agreed on the basis of the outcome of Stage 1 of the materials testing programme, the material is then subjected to a series of strength tests at three compactive efforts (Light, Intermediate and 
Heavy) and three moisture contents (Soaked, OMC and 0.75 OMC), i.e., a total of nine combinations of density and moisture content. In order to achieve relative compaction results of $\pm 98 \%, \pm 95 \%$ and $\pm 93 \%$, the following three compactive efforts used:

- Light: $2.5 \mathrm{~kg}$ rammer, 3 layers, 55 blows/layer

- Intermediate: $4.5 \mathrm{~kg}$ rammer, 5 layers, 25 blows/layer

- Heavy: $4.5 \mathrm{~kg}$ rammer, 5 layers, 55 blows/layer

The compacted samples should be allowed to equilibrate for at least 3 days ( 7 days for pedogenic materials) to allow pore-water pressures and compaction stresses to dissipate and to allow the moisture content to equilibrate within the sample. At each combination of density and moisture content, a laboratory DN test is carried out to determine the strength of the soil. The set-up for undertaking the laboratory DN test is illustrated in Figure 8.

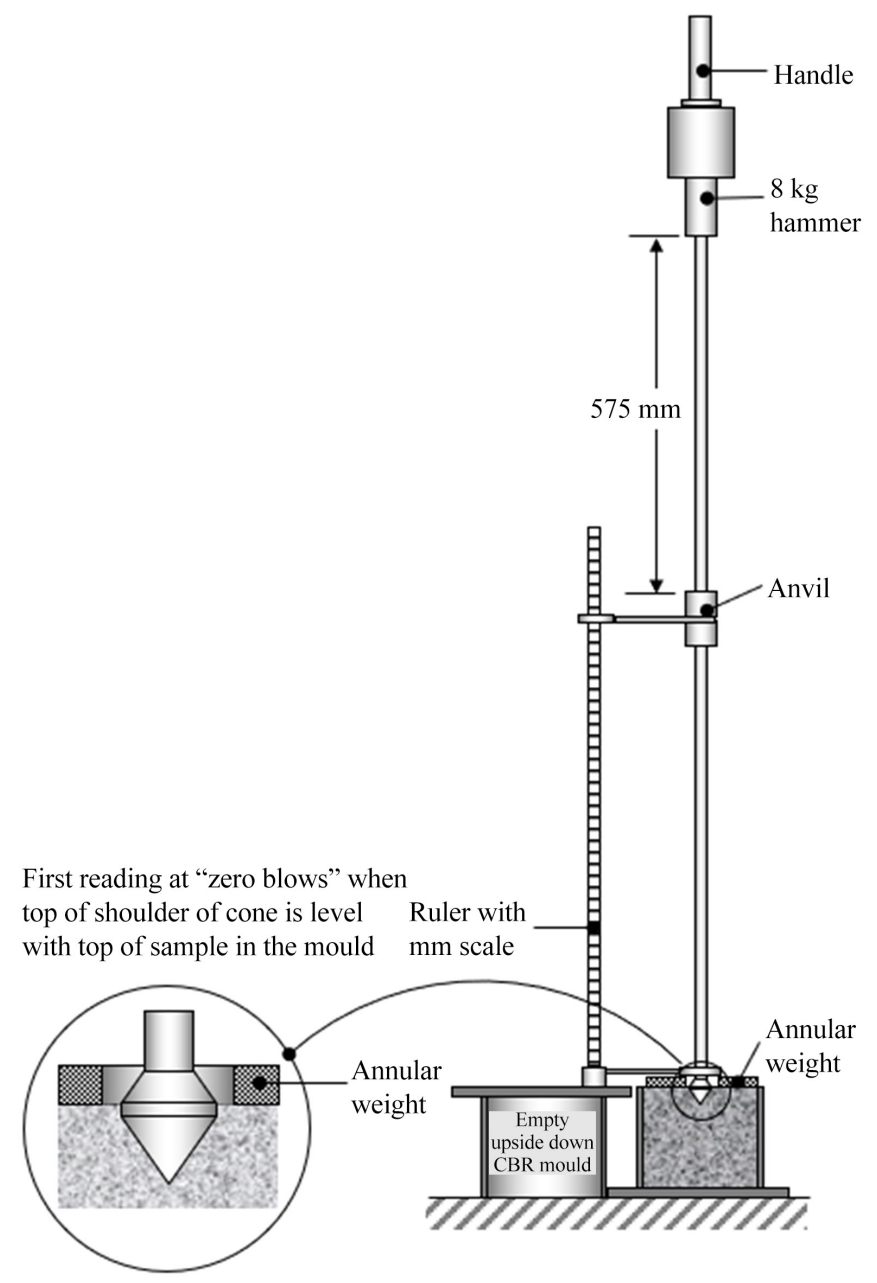

Figure 8. Set-up for laboratory DN test [35].

The results of the DN testing for each combination of density and moisture content can then be used to determine their inter-relationship, as illustrated typically in Figure 9. 

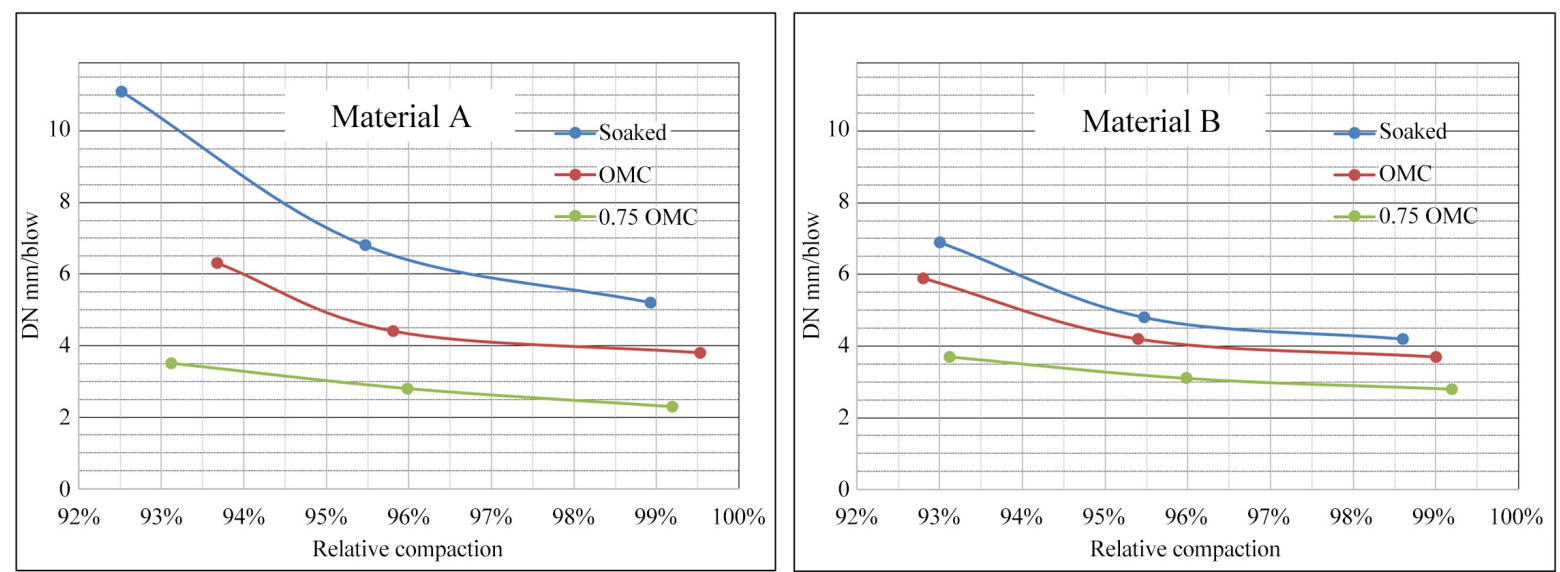

Figure 9. DN/density/moisture relationship for two different materials [35].

Figure 9 illustrates the typical outputs of the laboratory DN test programme for two different materials. The shape and separation of the curves are material dependant and will assist the engineer in undertaking a risk assessment, as explained below. As discussed above, an acceptable DN value(based on the design assumptions) takes account of the key interacting variables that affect material strength. Thus, acceptable grading and plasticity requirements are implicitly controlled by the DN value and need not be separately specified when selecting pavement layer materials, thereby reducing the risk of accumulating errors associated with specifying multiple material properties.

\section{Stage 3-Risk Assessment}

Assessing the risk profile of a material concerning how well suited it is to the design application is an essential aspect of the overall evaluation process. Such risk would be related, in part, to the sensitivity of the material's strength to changes in moisture and/or density and the implications this could have on pavement performance. This risk can be assessed from the output of Stage 2 of the laboratory testing programme (Figure 9) in which the gradient of the curves and the separation between them indicate the following about the particular material:

- The greater the vertical separation of the lines, the greater the sensitivity of the material's strength to moisture changes (a function of plasticity), and the greater the likelihood of poor performance should the moisture content increase significantly above that assumed for design purposes. To reduce the risk of such an occurrence, a number of measures can be considered, including:

o Sealing of shoulders to avoid lateral moisture ingress into the pavement's vulnerable outer wheel path areas.

o Deepening side drains and/or raising embankments to ensure a minimum crown height (vertical distance between the crown of the road and the invert of the side drain) to at least $0.65 \mathrm{~m}$ to $0.75 \mathrm{~m}$ depending on the gradient of the road. 
- The steeper the slope of the lines, the greater the sensitivity of the material's strength to changes in density (a function of particle size distribution and shape); and the greater the likelihood of poor performance should the specified density not be achieved during construction. To minimise the risk of such an occurrence, a number of measures can be considered, including:

o Compacting the subgrade and pavement layers to the highest practicable possible ("compaction to refusal") without material degradation, rather than to a pre-defined relative compaction level, as traditionally specified. This approach is likely to produce a significant gain in density, strength and stiffness, and reduction in permeability at minimal additional cost, thereby enhancing the material's overall properties and performance.

o Ensuring adherence to the specified pavement layer thickness and minimum compaction requirements by enforcing rigorous quality control measures on site. The DCP method of compaction control offers a viable alternative to the traditional methods such as Sand Replacement, core cutter, rubber balloon and nuclear density gauge [36]. These tests can be slow, hazardous, of uncertain accuracy, and impractical in situations where there is variation in site materials along the tested section.

By way of example using the two diagrams in Figure 9.

- The risk associated with an increase in moisture content from OMC to soaked is clearly greater for Material A than for Material B because of the larger difference in DN values between OMC and soaked for Material A. In a dry/moderate environment with good drainage conditions, Material A may therefore be acceptable, whereas in a wet environment with a high risk of saturation of the pavement, only Material B would be acceptable.

- The risk associated with not achieving the specified compacted density of the base layer of $98 \%$ is insignificant for both materials since those parts of the curves, at all moisture contents, are fairly flat. However, at lower compacted densities, say $95 \%$, which is normally specified for the subbase, the risks increase since the DN values increase (and strength decreases) significantly with a drop in density from $95 \%$ to $94 \%$ for both materials at OMC and in the soaked condition. This underscores the importance of achieving the minimum specified compacted densities, particularly at lower compacted densities. It also highlights the potential benefits of compacting to refusal the subgrade and pavement layers.

The risk assessment process should also consider several other in-service factors that could significantly influence pavement performance. These include:

Construction techniques: Generally, it is beneficial to allow the pavement to dry back to close to its equilibrium moisture content (EMC), typically below OMC [37], before it is sealed. This will allow the strength gain caused by suction [12] to be mobilized soon after compaction, rather than gradually over time, as would occur if the pavement had been sealed at OMC. By adopting this con- 
struction technique, the risk of using naturally occurring materials can be reduced, or a factor of safety achieved if, during the design process, the strength of the material is based on that obtained at OMC rather than at EMC.

Vehicle overloading: LVRs are prone to excessive deformation and shear failure due to overloading. A single, excessively loaded axle can cause the pavement to deform severely and fail, particularly if the pavement's moisture content rises and excessive pore-water pressures develop. However, this risk can be reduced by allowing the pavement layers to dry back and designing them as described above. If adequate overload control is unlikely to be achieved in practice, then a more substantial pavement should be provided.

Maintenance: LVRs are particularly vulnerable to inadequate or deferred maintenance due to the extensive use of local, often moisture-sensitive materials for pavement construction. This vulnerability is further exacerbated by the projected climate changes in the coming decade. Thus, the highest priority should be given to timely, adequate maintenance of LVRs to avoid their premature deterioration.

\subsection{Validation of Evaluation Framework}

The materials evaluation framework described above was developed on the basis of the research evidence emanating from the back-analysis of the in-service performance of a large number of test sections [2] [3] [4] [5] located in East, West and Southern Africa.

The framework has also been successfully applied in the design of more than $2600 \mathrm{~km}$ of LVRs in South Africa [38] and, more recently, under ReCAP in several countries in West and Southern Africa [39]. In all cases, the materials were subjected to the three-tier evaluation procedure described above and, in general, the roads have performed satisfactorily. The majority of sealed low volume roads constructed since the early 1980s are still providing excellent service, except where routine maintenance has been neglected, typically due to lack of timeous resealing of the non-structural bituminous surfacing resulted in the surface rather than structural failures.

\subsection{Impact of Adopting the Materials Evaluation Framework}

\subsubsection{Material specifications}

Provided all materials are assessed as suitable from the outcome of the Stage 1 evaluation procedure discussed above, then the two parameters that need to be specified for the imported pavement layers are as follows:

- Grading modulus: The inclusion of this parameter as a specification criterion is to exclude any materials that are patently unsuited for use in a pavement layer in terms of their very poor grading and/or very high fines content, e.g., very fine soils that are likely to be plastic soils, or very poorly graded 
gravels which, in any case, would most probably not satisfy the required DN value. A typical value is $1.0 \leq \mathrm{GM} \leq 2.25$ [35].

- DN value: The acceptance criterion for a material is the laboratory $\mathrm{DN}$ value at a specified minimum density and the anticipated in-service equilibrium moisture content of the pavement in service for various layers of the DCP-DN catalogue.

The DCP-DN catalogue was developed from extensive research carried out in South Africa from the mid-1970s onwards [40] and, more recently, was enhanced under ReCAP [35]. The catalogue stipulates a required laboratory DN value at a specified minimum density and the anticipated in-service equilibrium moisture content of the pavement for various design traffic loading classes up to one million equivalent standard axles.

The philosophy behind the DCP-DN design method is to achieve a balanced pavement design while also optimising the in-situ material strength utilization as much as possible [41]. In this approach, the DCP is used to evaluate the existing in situ road conditions and, by integrating the design strength profile with the in-situ strength profile, designing LVR pavement structures in a highly cost- effective manner.

\subsubsection{Road Construction Costs}

The DCP-DN specifications widen the scope for using local materials and contribute to reduced construction costs by minimising haul distances and material extraction and processing costs. This likelihood was confirmed from a study to determine the cost-effectiveness of the DCP-DN design method compared to other, more traditional, CBR-based LVR design methods. The study found that the DCP-DN method was the most cost-effective design option at design traffic loadings up to about 0.7 MESA and across all subgrade strengths and climatic zones [42].

\section{Summary and Conclusions}

The successful and economical utilisation of local materials in LVR pavements depends on their proper characterization, not only in terms of their properties, but also in the traffic loading, physical environment, and their interactions. Unfortunately, a conflict often exists between material acceptability, as defined by conventional test methods and specifications, and material suitability in terms of actual engineering performance. This has led to a need to develop a more reliable, performance-related materials evaluation framework for selecting and specifying local materials and, ultimately, facilitating their optimised utilisation in the design and construction of LVRs.

The proposed framework includes a three-tier evaluation procedure. The materials are initially screened based on classification, mineralogical, and durability tests to eliminate those patently unsuitable for use in the LVR pavement structure. After that, the strength of the material is determined based on its DCP 
penetration rate in $\mathrm{mm} / \mathrm{blow}$, or $\mathrm{DN}$ value.

The evaluation framework was developed from research carried out over many decades, starting in the mid-1990s, based on the back-analysis of many LVRs and has subsequently been validated through the successful design of more than $2600 \mathrm{~km}$ of LVRs in several African countries. In conjunction with the DCP-DN design method, the evaluation framework's use offers the potential to significantly reduce the cost of road construction, particularly in rural and remote areas and for low volume traffic roads through improved utilisation of locally available materials.

\section{Areas of Further Research}

There are several areas of further research that would expand on the work carried out previously by others, as referenced in the paper, well as provide additional insights into the use of the DCP device, including:

- Precision limits for Lab DN test.

- Laboratory DN and Tri-axial tests on a broader range of materials than those investigated by Ayers et al. [29], to determine the correlation between DN and shear strength (repeat of US test, but with a broader range of and different materials).

- Robustness of DN test in terms of:

o The influence of scalping the material at $20 \mathrm{~mm}$ versus crushing and inclusion of the oversize fraction.

o The effect of the incorrect test procedure (DCP not vertical, blunt/worn cone, etc.).

o A comparison of the field $\mathrm{DN}$ and laboratory $\mathrm{DN}$ tests under identical conditions to determine the influence of confinement in the CBR mould for different materials, and at different densities.

\section{Acknowledgements}

The paper was prepared as part of a ReCAP project [33], and the support provided by the organization is gratefully acknowledged, as well as the comments made by Dr. Samuel Ampadu of the ReCAP Technical Panel. In addition, valuable comments were also provided by Messrs. John Rolt, Gerrie van Zyl, Martin Mgangira, Tyrone Toole, Ian van Wijk, Morris de Beer and Frank Netterberg.

\section{Conflicts of Interest}

The authors declare no conflicts of interest regarding the publication of this paper.

\section{References}

[1] Rice, Z. and Toole, T. (2020) Sustainable Roads through Fit-for-Purpose Use of Available Materials: Technical Basis. Austroads Publication No. AP-T352-20, Sydney. 
[2] Gourley, C.S. and Greening, P.A.K. (1999) Performance of Low-Volume Sealed Roads; Results and Recommendations from Studies in Southern Africa. TRL Project Report PR/OSC/167/99, Crowthorne.

[3] Paige-Green, P. (1999) Materials for Construction of Sealed Low Volume Roads. Journal of the Transportation Research Board, 1652, 163-171. https://doi.org/10.3141/1652-21

[4] Rolt, J., Mukura, K., Dangare, F. and Otto, A. (2013) Back Analysis of Previous Low Volume Rural Roads in Mozambique. AfCAP/MOZ/001/G. Final Report RPN2585.

[5] Rolt, J., Otto, A., Mukura, K., Reeves, S., Hine, J., Musenero, L., TRL Limited (2020) Rural Road Note 01: A Guide to the Application of Pavement Design Methods for Low Volume Rural Roads. ReCAP for UK Aid, London.

[6] Garg, N. and Thompson, M.R. (1997) Triaxial Characterization of Minnesota Road Research Project Granular Materials. Transportation Research Record, 1577, 27-36. https://doi.org/10.3141/1577-04

[7] Pupalla, A.J. (2008) Estimating Stiffness of Subgrade and Unbound Materials or Pavement Design. NCHRP Synthesis 382, TRB, National Research Council, Washington DC.

[8] Magnusdottir, B. and Erlingsson, S. (2003) Repeated Load Triaxial Testing for Quality Assessment of Unbound Granular Base Course Materials.

http://iii.is/aggregate/abstracts_12.pdf

[9] Southern Africa Development Community (SADC) (2003) Guideline: Low-Volume Sealed Roads. SADC House, Gaborone.

[10] Toole, T., Rice, Z., Latter, L. and Sharp, K. (2018) Sustainable Roads through Fit-for-Purpose Use of Available Materials. Austroads Publication No. AP-T333-18, Austroads Ltd., Sydney.

[11] Cook, J.R., Bishop, E.C., Gourley, C.S. and Elsworth, N.E. (2002) Promoting the Use of Marginal Materials. DfID KaR Project. PR/INT/205/2001 R6887, TRL, Crowthorne, Berkshire.

[12] Toll, D.G. (2012) The Behaviour of Unsaturated Soils. In: Huat, B.B.K., Toll, D.G. and Prasad, A., Eds., Handbook of Tropical Residual Soils Engineering, CRC Press, Leiden, Chapter 5.

[13] Committee of Land Transportation Officials (COLTO) (1997) Standard Specifications for Road and Bridge Works for State Road Authorities. SAICE, Johannesburg.

[14] Saaed, A., Hall, J.W. and Barker, W. (2001) NCHRP Report 453: Performance-Related Tests of Aggregates for Use in Unbound Pavement Layers. Transportation Research Board, National Research Council, Washington DC, 1-56.

[15] Porter, O.J. (1938) The Preparation of Subgrades. HRB Proceedings, 18, 324-331.

[16] Millard, R.S. and O'Reilly, M.P. (1964) Standards of Road Building Practice in the Tropics. Proceedings of 2nd Australian Road Research Board Conference, Vol. 2 (Part 2), 850-854.

[17] Rallings, R. (2014) CBR Test-A Case for Change? Australian Geomechanics, 49, 41-55.

[18] Sukumaran, B., Kyatham, V., Shah, A. and Sheth, D. (2002) Suitability of Using California Bearing Ratio Test to Predict Resilient Modulus. Federal Aviation Administration Airport Technology Transfer Conference, Atlantic City, New Jersey, May 2002.

[19] Thompson, M.R. and Robnett, Q.L (1979) Resilient Properties of Subgrade Soils. Journal of Transportation Engineering, 105, 71-89. 
[20] Heukelom, W. and Klomp, A.J.G. (1962) Dynamic Testing as a Means of Controlling Pavement during and after Construction. Proceedings of the 1 st International Conference on the Structural Design of Asphalt Pavement, Ann Arbor, Michigan, 20-24 August 1962, 667-685.

[21] Powell, W.D., Potter, J.E., Mayhew, H.C. and Nunn, M.E. (1984) The Structural Design of Bituminous Roads. TRRL Report LR 1132.

[22] Brown, S.F., Loach, S.C. and O'Reilly, M.P. (1987) Repeated Loading of FineGrained Soils. University of Nottingham, Nottingham.

[23] Boateng, J.A., Tutumluer, E., Apeagyei, A. and Ochieng, G. (2009) Resilient Behavior Characterisation of Geomaterials for Pavement Design. 11 th International Conference on Asphalt Pavements, Nagoya, 1-6 August 2010.

[24] Cocks, G., Keeley, R., Leek, C., Foley, P., Bond, T., Cray, A., Paige-Green, P., Emery, S.J., Clayton, R., McInnes, D. and Marchant, L. (2015) The Use of Naturally Occurring Materials for Pavements in Western Australia. Australian Geomechanics, 50, 43-106.

[25] American Society for Testing Materials (ASTM) (2018) Standard Test Method for the Use of the Dynamic Cone Penetrometer in Shallow Pavement Applications: ASTM D6951/D6951M-18. ASTM International, West Conshohocken.

[26] Livneh, M. (1987) The Use of the Dynamic Cone Penetrometer in Determining the Strength of Existing Pavements and Subgrade. Proceedings, 9th Southeast Asian Geotechnical Conference, Bangkok, 7-11 December 1987, 2, 1-9.

[27] Smith, R.B. and Pratt, D.N. (1983) A Field Study of In-Situ California Bearing Ratio and Dynamic Cone Penetrometer Testing for Subgrade Investigation. Australian Road Research, 13, 285-293.

[28] Harison, J.A. (1989) Correlation between California Bearing Ratio and Dynamic Cone Penetrometer Strength Measurements of Soils. Australian Road Research, 19, 130-136. https://doi.org/10.1680/iicep.1989.1457

[29] Ayers, M.E., Thompson, M.R. and Uzarski, D.R. (1989) Rapid Shear Strength Evaluation of in Situ Granular Materials. Journal of the Transportation Research Board, 1227, 134-146.

[30] George, K.P. and Uddin, W. (2000) Subgrade Characterisation for Highway Pavement Design. University of Mississippi, Dept. of Civil Engineering, Oxford.

[31] De Beer, M. (1991) Use of the Dynamic Cone Penetrometer (DCP) in the Design of Road Structures. Proceedings of the 10 th Regional Conference for Africa on Soil Mechanics and Foundation Engineering, Maseru, 23-27 September 1991, 167-176.

[32] Lee, I.K., White, W. and Ingles, O.G. (1983) Geotechnical Engineering. Pitman Publishing Inc., Massachusetts, 62.

[33] Holtz, W.G. and Gibbs, H.J. (1956) Engineering Properties of Expansive Clays. Transactions of American Society of Civil Engineers, 121, 641-663.

[34] Seed, H.B., Woodward, R.J. and Lundengren, R. (1962) Prediction of Swelling Potential for Compacted Clays. Journal of Soil Mechanics and Foundation Engineering, ASCE, 93, 325-353.

[35] Pinard, M.I. and Hongve, J. (2020) Pavement Design of Low Volume Roads Using the DCP-DN Method. ReCAP for UKaid, London.

[36] Livneh, M. and Livneh, N. (2013) The Use of the Dynamic Cone Penetrometer for Quality Control of Compaction Operations. International Journal of Engineering Research in Africa, 10, 49-64.

https://doi.org/10.4028/www.scientific.net/JERA.10.49 
[37] Emery, S.J. (1985) Prediction of Moisture Content for Use in Pavement Design. PhD Thesis, University of Witwatersrand, Johannesburg.

[38] Van Zyl, G.D. and Burger, R. (2019) A Review of Experience on $2600 \mathrm{~km}$ of Low Volume Surfaced Roads in South Africa. Low Volume Sealed Roads Workshop, National Roads Administration (ANE) with Association of Southern African National Roads Agencies (ASANRA), 22-24 September 2008, Maputo.

[39] Geddes, R. and Pinard, M. (2020) Capacity Building and Mentorship for the Establishment and Implementation of Monitoring \& Evaluation Programmes on Experimental and Long-Term Pavement Performance (LTPP) Sections in Six African Countries and Myanmar. Final Report, GEN2132A, ReCAP for DFID, London.

[40] Paige-Green, P. and Van Zyl, G.D. (2020) A Review of the DCP-DN Pavement Design Method for Low Volume Roads: Development and Applications. Journal of Transportation Technologies, 9, 397-422 https://www.scirp.org/journal/itts https://doi.org/10.4236/jtts.2019.94025

[41] Kleyn, E.G. and Steyn, W.J. vd M. (2011) Pavement Strength Balance and Its Practical Implications. 10th Conference on Asphalt Pavements for Southern Africa, KwaZulu-Natal, 11-14 September 2011.

[42] Pinard, M.I., Van Zyl, G.D. and Hongve, J. (2019) Evaluation of Cost-Effectiveness and Value-for-Money of DCP-DN Pavement Design Method for Low-Volume Roads in Comparison with Conventional Designs. Final Report RAF 2128A, ReCAP for UKaid, London. 